\title{
DIETA NEOLIBERAL Y DESIGUALDAD EN LOS PAÍSES DEL TLCAN: ¿CONVERGENCIA O DIVERGENCIA ALIMENTARIA?
}

\author{
Gerardo Otero* \\ Gabriela Pechlaner**
}

RESUMEN: A principios de los años noventa, una de las preguntas que incendiaban las discusiones sobre la posibilidad del Tratado de Libre Comercio de América del Norte (TLCAN) era si habría convergencia hacia abajo, en el nivel del desarrollo mexicano, o hacia arriba, en el de Canadá y Estados Unidos. Quienes abogaban por el TLCAN sugerían que la convergencia sería hacia arriba, los detractores decían lo contrario. Después de 20 años, contamos con suficientes datos empíricos para evidenciar lo que en realidad ha sucedido. En relación con la agricultura y la alimentación, los patrones dietéticos estadounidenses se han consolidado: tales patrones ya se daban de manera diferenciada, con las clases de ingresos medios y altos que compraban los alimentos de mayor valor agregado; $y$ las más pobres, los más baratos y densos en contenido energético. Lejos de darse una convergencia en cualquier sentido, sugerimos que se ha dado una «convergencia diferenciada» en función de las clases sociales. El comercio internacional ha crecido entre los tres países, pero con patrones que expresan una dominación de Estados Unidos sobre sus vecinos. Los patrones de consumo muestran también la convergencia diferenciada. Esbozamos la neorregulación en la región del TLCAN, el contraste de las experiencias de los tres países, los patrones de consumo junto con la globalización de la agricultura, la producción alimentaria, la convergencia y divergencia en la agricultura, así como el desarrollo en la región del TLCAN.

PALABRAS ClAVE dieta neoliberal, agricultura, dependencia alimentaria, clases sociales, TLCAN.

* Profesor de Simon Fraser University, Canadá.

** Profesora de University of the Fraser Valley, Canadá. 
ABSTRACT: In the early 1990s, one of the questions that set fire to debates on the possibility of a North American Free Trade Agreement (NAFTA) was whether it would result in a convergence from below, at the level of Mexican development, or rise toward the levels of Canada and the United States. Those who argued for the NAFTA suggested that the convergence would trend upward, while the detractors foresaw the opposite. After 20 years of NAFTA, we have sufficient data now to show what really has happened. With regard to agriculture and nutrition, U.S. dietary patterns have consolidated: the patterns are provided in a differentiated manner, with medium- and high-income classes favoring foods of greater added value, and the poorest buying the cheapest food with greater caloric density. Far from being a convergence in any sense, we suggest that a «differentiated convergence» has been created based on social class. International commerce has grown among the three countries, but the patterns show a domination of its neighbors by the United States. The patterns of consumption also show a differentiated convergence. We outline the neo-regulation in the region comprising NAFTA, the contrasting experiences of the three NACLA signatories, the patterns of consumption that occurred in those countries with the implementation of globalization in agriculture and food production, and the convergence and divergence in agriculture and in development across the NAFTA region.

KEYWORDS: neoliberal diet, agriculture, food dependency, social classes, NAFTA. 
omo lo sugiere el dicho chino, vivimos «tiempos interesantes», y agregaríamos que son profundamente interesantes para la agricultura y la alimentación. El grado de «interés» es producto de una dinámica contradictoria sin límites que golpea la producción y el consumo de alimentos - producto de diversos imperativos económicos-y del hecho insulso de la dependencia alimentaria. Por el lado de la producción, desde finales de los años ochenta hemos estado inmersos en una liberalización desigual del comercio agrícola, con la industrialización de las agriculturas de los países en desarrollo y la concomitante urbanización de sociedades otrora agrarias. Una parte significativa del paquete liberalizador y agroindustrializador ha sido la consolidación de las agroempresas multinacionales (AEM) en tanto organizadoras y beneficiarias de la emergente división internacional del trabajo agrícola (McMichael, 2009a; Pechlaner y Otero, 2010; Appendini, 2014). Los cultivos transgénicos son otro componente clave de la agroindustrialización y desempeñan un papel significativo en las estrategias globales de acumulación de las AEM, a la vez que se debilita la invisibilidad con la que operan (Pechlaner, 2012).

Dicha dinámica ha de hacerse cada vez más «interesante». El crecimiento poblacional seguirá ejerciendo presión sobre una producción en aumento, mientras que nuevos desafíos - como el cénit del petróleo, el cambio climático y la escasez de tierra - amenazan con disminuirla. Cada una de estas presiones fomenta nuevas maniobras económicas y de poder, como lo atestigua el acaparamiento de tierras en varios continentes (véase, por ejemplo, Borras, Hall, Scoones, White y Wolford, 2011). Además, el consumo también tiene su nutrida dinámica, ligada fuertemente con la producción. Culturalmente, los ciudadanos están más y más enajenados de la producción alimentaria, y las comidas no sólo se cocinan cada vez menos, sino que se ensamblan de acuerdo con las instrucciones del embalaje. Este proceso se conforma con lo que llamamos la dieta neoliberal, que se manifiesta en productos comestibles de alto contenido calórico y bajo valor nutritivo (Otero, Pechlaner y Gürcan, en prensa). Además, las desigualdades internacionales se replican en la producción agrícola dentro de las naciones, con patrones de 
consumo divergentes entre los consumidores ricos con alimentos especializados y de nicho (Johnston y Baumann, 2010) y los más pobres y de ingresos medios que se convierten en receptáculos de los alimentos preparados en masa (Friedmann, 2005; Dixon, 2009; Guthman, 2011; Winson, 2013).

Ciertamente, estas dinámicas de producción y consumo se han visto sujetas a contra-presiones de una amplia gama de opositores: orgánicos, comercio justo, pro-campesino, antitransgénicos y varios movimientos a favor de estilos de vida saludables, por nombrar algunos. Hasta el momento, dicha oposición no ha acertado a modificar la dinámica de lo que hemos llamado el régimen alimentario neoliberal (Otero, 2014), pero han puesto pequeñas nubes en el horizonte de las estrategias de acumulación de las AEM. Algunas tienen un significativo potencial de perturbación, como los movimientos locales que exigen el etiquetado de alimentos que contengan organismos genéticamente modificados en Estados Unidos (Pechlaner, 2012; Walsh-Dilley, 2009) o las presiones de los movimientos sociales en México que han propiciado que los magistrados impongan moratorias para la liberación del maíz transgénico de Monsanto (Wise, 2014).

En suma, la multiplicidad y complejidad de las fuerzas que afectan la producción y diseminación de la comida hacen que sea extremadamente difícil predecir la tendencia de la producción alimentaria. Es obvio que no todos los procesos señalados son producto de la globalización. No obstante, ésta tiene un papel innegable en muchos de ellos, particularmente en el carácter neoliberal de la liberalización comercial y la neorregulación que le acompaña, es decir, las nuevas formas de intervención del Estado para instigar la globalización. Nuestra meta aquí es enfocarnos en una región clave de esta dinámica de globalización neoliberal, representada por Canadá, México y Estados Unidos, los tres países que componen el Tratado de Libre Comercio de América del Norte (TLCAN). Esta es una región central en la economía política global de la agroalimentación, pues tanto Canadá como Estados Unidos tienen una larga tradición como potencias agroexportadoras en la economía mundial. 
Además, este último es el productor dominante de las tecnologías agrícolas y principal defensor de la liberalización comercial, mediante las cuales se diseminan sus patrones dietéticos.

Por su parte, México puede ser el ejemplo más radical de adopción de la doctrina neoliberal, en la cual la liberalización comercial es un componente central, sobre todo en la agricultura. Así pues, si bien el creciente comercio agrícola es un fenómeno global con diferentes grados y profundidades, el TLCAN nos ofrece un buen ejemplo de los cambios que ocurren como resultado de la globalización neoliberal y sus efectos contrastantes entre países con diferentes niveles de desarrollo socioeconómico y poder estatal.

En este artículo argumentamos que, lejos de que se haya dado una convergencia total en comercio agrícola, dietas y desarrollo, lo que ha resultado en la región del TLCAN es un proceso de «convergencia diferenciada». El comercio agrícola se ha incrementado en los tres países, pero no de manera simétrica, sino con patrones que muestran claramente que Estados Unidos es el jugador dominante. Los patrones de consumo también muestran una convergencia diferenciada, con un creciente consumo de carnes en los tres países, sobre todo de pollo; sin embargo, el consumo de carne de res va en aumento en México y en decrecimiento en Canadá y Estados Unidos.

En la primera sección esbozamos las posturas neorregulatorias de la región del TLCAN, poniéndolas en el contexto de la literatura del régimen alimentario. Luego presentamos los principales patrones comerciales usando datos macro de la Organización de las Naciones Unidas para la Alimentación (FAO, por sus siglas en inglés), contrastando las experiencias de los tres países de la región. Enseguida describimos los cambiantes patrones de consumo alimentario en estos países, mismos que ocurren junto con la globalización de la agricultura y la producción alimentaria. Por último, discutimos estos datos en relación con la convergencia y divergencia en agricultura y desarrollo en la región del Tratado de Libre Comercio de América del Norte. 


\section{EL TLCAN COMO RÉGIMEN ALIMENTARIO REGIONAL}

En los días iniciales, los defensores de este Tratado promovían los méritos para las tres naciones. Mickey Kantor, el representante comercial estadounidense, por ejemplo, afirmó que «toda la idea del TLCAN es hacer a Norteamérica más competitiva y que va a crear más empleos» (Fagan, 1994). No sólo los intereses estadounidenses promocionaban tal perspectiva. Jaime Serra Puche (1994), secretario de Comercio mexicano, por ejemplo, insistía que «el nuevo acceso para las compañías mexicanas a Canadá y Estados Unidos acelerará el crecimiento económico mexicano en todas partes del país». En efecto, la teoría económica neoclásica predice que el aumento del comercio entre las naciones llevará a su complementariedad y convergencia. La experiencia real de la integración de los tres socios del TLCAN, sin embargo, ha generado divergencia en los resultados del desarrollo socioeconómico entre México y los dos países más ricos.

Las metas económicas explícitas del Tratado - aumentar el comercio y la inversión extranjera - se han cumplido de forma diferenciada: el comercio ha aumentado más allá de las expectativas, al multiplicarse por cinco o seis (según se trate de exportaciones o importaciones), pero la inversión extranjera ha crecido mucho más en los dos países más ricos que en México. Además, las metas socioeconómicas del país se han quedado muy cortas con el aumento en el número y proporción de gente en situación de pobreza y mayor desigualdad (Acosta, 2014). Respecto a la agricultura, aun los más fervientes porristas neoliberales han tenido que admitir los efectos significativamente negativos para México. Las repercusiones del neoliberalismo fueron mucho más pronunciadas en México puesto que tenía más gente que dependía de la agricultura, y Estados Unidos retuvo su jugoso nivel de subsidios al sector agrícola. En consecuencia, hay evidencia sobrada de divergencia en la industrialización agrícola que ha tenido efectos sociales significativos a la vez que aumentó la vulnerabilidad alimentaria de los mexicanos (González, 2013; Otero, 2014). Sin embargo, tal divergencia no ha sido consistente. La convergencia más significativa ha sido del patrón alimentario, específica- 
mente en la globalización de la dieta estadounidense, la cual discutimos enseguida. Pero antes de revisar la dinámica de los datos sobre comercio y consumo, presentamos brevemente el contexto analítico en la literatura del régimen alimentario.

La perspectiva del régimen alimentario desarrollada por Harriet Friedmann y Philip McMichael (véase, por ejemplo, Friedmann, 1992, 2005; Friedmann y McMichael, 1989; McMichael, 1992, 2005, 2009a, 2009b) ofrece un enfoque multifacético — geográfico, histórico y político- para entender las relaciones internacionales en la producción y diseminación de la agricultura y los alimentos. La principal fortaleza es la habilidad de conjuntar estas facetas para articular regímenes o periodos distintivos de estabilidad en las relaciones globales de la agricultura y la alimentación. Por ejemplo, el régimen Colonial de 1870 a 1914, con hegemonía británica, caracteriza un tiempo de construcción nacional entre los Estados de colonos y las metrópolis industriales y articula las relaciones de provisión alimentaria que se forman en torno a esta dinámica. La base productiva es la extensión de la frontera agrícola. En contraste, el régimen superavitario caracterizó un periodo de hegemonía estadounidense, agriculturas nacionales (subsidiadas y con exención de las reglas del comercio internacional) y superávit de granos que sentó las bases para la dependencia de los países en desarrollo de las importaciones desde Estados Unidos. La base productiva se funda en lo que se ha llamado la agricultura moderna, basada en las nuevas variedades vegetales como los cultivos híbridos, la mecanización, los agroquímicos, el monocultivo, etcétera (Otero, 2014).

Hemos argüido en otros lugares que el enfoque del régimen alimentario es más efectivo en el análisis histórico que en la habilidad predictiva (Otero, 2014; Pechlaner y Otero, 2008, 2010; Otero, Pechlaner y Gürcan, 2013). Los fundadores sí articulan cómo los periodos de crisis entre regímenes son oportunidades para que una multiplicidad de influencias conforme al nuevo régimen en formación. En consecuencia, las diversas evaluaciones sobre la naturaleza del tercer régimen alimentario emergente están asentadas en un peso distinto asignado a tales 
influencias. Las características centrales que se le han reconocido consistentemente al nuevo régimen a partir de los años ochenta del siglo $\mathrm{xx}$ son, sin embargo, sus dinámicas neorregulatorias. Éstas reducen o eliminan las barreras al comercio sobre bases ambientales o de seguridad alimentaria, fortalecen los derechos de propiedad intelectual y promueven un papel central para las АЕм en la producción y distribución de alimentos, y en conjunto profundizan la liberalización comercial. La mayor consolidación de las agroempresas ha ocurrido a tal grado que McMichael lo caracteriza como nuevo «régimen empresarial» (corporate regime) (2009a). Puesto que el Estado sigue siendo un facilitador central de dicha consolidación, sin embargo, aquí se ha designado este régimen como «régimen alimentario neoliberal». La principal característica regulatoria no es la desregulación, como lo plantea McMichael, sino lo que se ha denominado neorregulación. Richard Snyder (2001) captó el contenido específico de la regulación estatal en México y la llamó «rerregulación», pero este término implica que la nueva regulación simplemente regresó a una existencia anterior, y no fue así. El Estado ha intervenido de manera distinta para facilitar la preeminencia de diferentes actores económicos en la agricultura, sobre todo de los capitalistas agrarios y las AEM, mientras que ha abandonado a los productores campesinos y desmantelado las agencias estatales que apoyaban los ingresos agrícolas y los precios al consumidor. Kirsten Appendini (2014) ha descrito magistralmente este proceso para el caso de la cadena mercantil del maíz en México.

Si bien muchas de las características de los regímenes alimentarios resultan tanto de dinámicas geopolíticas no escritas, realidades económicas y avances tecnológicos, la política comercial ha desempeñado un papel altamente significativo. Por tanto, el régimen alimentario de posguerra estuvo dominado por Estados Unidos, y sus prácticas proteccionistas y de subsidios fijaron el tono para el comercio agrícola global. Surgió así una clara diferenciación entre países que podían permitirse tales prácticas y los que no, cuyas mercancías debían competir contra otras de precios más bajos. Es así como la agricultura permaneció en un 
estado persistente de excepción dentro de la ideología de la liberalización comercial, y un tema de disputa en las negociaciones más amplias en la liberalización comercial.

Después del segundo régimen alimentario, hubo amplia oportunidad para que la política diera forma al tercero. En 1987, se inició una nueva ronda de negociaciones del Acuerdo General sobre Aranceles Aduaneros y Comercio (GATT, por sus siglas en inglés), el cual había estado vigente desde 1948. El resultado de la nueva ronda (la Ronda de Uruguay) fue el establecimiento en 1995 de la Organización Mundial del Comercio (омс), una institución de mayor alcance y estabilidad, que agregó nuevas áreas de regulación, tales como los derechos de propiedad intelectual. Esto último ha sido crucial para el desarrollo de la biotecnología agrícola, uno de los principales componentes de las estrategias de acumulación en la agricultura de Estados Unidos (Otero, 2014; Pechlaner, 2012). Si bien la om c ha tenido éxito en cuanto a facilitar varios aspectos del comercio internacional y ha tenido avances en la reducción de distorsiones en el comercio agrícola mediante su Acuerdo sobre la Agricultura, se ha quedado corta respecto a las expectativas de los más ardientes defensores de la liberalización comercial del sector. La Ronda de negociaciones de Doha, que se inició en 2001, por ejemplo, debía dar los últimos toques de liberalización de la agricultura, pero ha fallado en vista de la resistencia de los representantes de los países en vías de desarrollo ante el proteccionismo y los subsidios agrícolas de los países desarrollados.

Sin embargo, lo que no se ha logrado en la agricultura vía омс, se ha logrado efectivamente mediante el TLCAN, iniciado en 1994. Si bien el comercio agrícola entre Canadá, México y Estados Unidos no fluye sin restricciones, el Tratado supervisa una liberalización comercial agrícola significativa entre los países.

En suma, si bien han ocurrido cambios significativos en escala global y están bien consolidados en las características del régimen alimentario neoliberal, la manifestación plena de la neorregulación no ha alcanzado su expresión final. El TLCAN proporciona, no obstante, una 
manifestación regional importante de lo más desarrollado del régimen alimentario neoliberal. Una pregunta que queda por contestar es qué han significado estos cambios en el régimen alimentario neoliberal para la dieta de la gente, específicamente en la región del TLCAN: en qué medida dicta el régimen alimentario neoliberal un régimen dietético particular, a pesar de los obstáculos culturales que se pueda enfrentar.

Anthony Winson (2013) ha hecho algún esfuerzo por abordar esta pregunta. Argumenta que los regímenes dietéticos son complementarios aunque diferenciados de los regímenes alimentarios, puesto que tienen «sus propios énfasis y demarcaciones temporales» (Winson, 2013: 18). El primer régimen dietético sí se traslapa con el primer régimen alimentario, aunque Winson afirma que dura unas tres décadas más. Notablemente, ese régimen resultó de los significativos desarrollos tecnológicos, tales como el enlatado y la molienda de harinas para la refinación. Estas tecnologías permitieron el desarrollo de todo un rango de nuevos productos cada vez más procesados. Estos productos se lanzaron con un significativo mercadeo de masas, lo cual se ha convertido en una característica central del largo proceso de tránsito de los alimentos integrales, con muchos nutrientes esenciales, a productos industriales altamente procesados que carecen de los mismos (2013: 131). En pocas palabras, la industrialización de los alimentos ha resultado en su degradación.

Otra similitud que podemos observar entre regímenes dietéticos y alimentarios es que sus características sientan las bases para los sucesores. Las características centrales de los regímenes sucesores son el procesamiento industrial, el marketing masivo y las dietas degradadas. De hecho, su coherencia es parte de la distinción que hace Winson entre los regímenes dietéticos y alimentarios, argumentando que el segundo no está correlacionado con una transformación dietética. Más bien, promueve la intensificación de la dieta que había tomado forma en el régimen previo. Su dieta perpetúa la degradación nutricional de la comida. Se compone de alimentos altamente procesados, con alto contenido de grasas y azúcares, es decir, denso en energía, sin valor nutritivo (Drewnowski y Specter, 2004). Esto es lo que llamamos la dieta neoliberal 
(Otero et al., en prensa) y nótese que una característica es la marcada diferenciación de clase (véase, por ejemplo, Darmon y Drewnowski, 2008; Dixon, 2009; Lee, 2011).

Argumenta Winson que el tercer régimen dietético surgió después de 1980. Su característica más distintiva es la expansión global de la dieta estadounidense, de tal forma que conlleva un «dramático cambio cualitativo en la experiencia de comer, con los consiguientes resultados de sanidad, para todo un conjunto de poblaciones a través del mundo» (2013: 35). De hecho, el cambio dietético ha sido tan extenso que para los años noventa del siglo xx se le designó como «transición nutricional», y su avance ha sido ampliamente facilitado por el surgimiento de los aceites vegetales baratos, cuyo uso es ubicuo en la industria del procesamiento y la comida rápida. Aun en países como China y Japón, donde el consumo de grasas animales nunca fue tan alto como el de los aceites vegetales, el consumo de estos últimos ha aumentado drásticamente desde finales de los años setenta. El consumo promedio per cápita diario de aceites vegetales en China subió de 64 kilocalorías en 1979 a 216 en 2009, mientras que las cifras para Japón subieron de 226 a 361 kilocalorías en el mismo periodo, un incremento de 238 por ciento y 60 por ciento, respectivamente (calculado con datos de FAOSTAT).

Hay evidencia significativa de que a la globalización de la dieta neoliberal corresponde también la exportación de sus efectos negativos para la sanidad que ya eran comunes en Estados Unidos. La tasa de obesidad en México (32.8 por ciento), por ejemplo, supera ya la de Estados Unidos (31.8 por ciento) (Althaus, 2013). Más aún, tenemos todas las razones para creer que las inequidades dietéticas evidentes en Estados Unidos se replicarán como manifestación de su exportación dietética - aunque la demarcación clasista será más compleja en países en desarrollo, donde muchos de los alimentos procesados serán prohibitivamente caros para la gente de más bajos ingresos. Los mayores riesgos en estos países serán para las clases trabajadoras de ingresos medios. Se discutirá la cuestión de las clases y la dieta en la siguiente sección. 


\section{DIETA Y COMERCIO EN LA REGIÓN DEL TLCAN:} CONVERGENCIA Y DIVERGENCIA

Si las únicas metas del Tratado hubiesen sido aumentar el comercio y las inversiones, entonces fue todo un éxito, aunque más modesto en el último aspecto para México. No cabe duda de que el comercio aumentó drásticamente: para 2012, los flujos de importación y exportación fueron 5.3 veces mayores que los de 1994. Las exportaciones se multiplicaron por 6.1 y las importaciones por 4.7, lo cual confirió a México un gran poder exportador y ofreció a muchos mexicanos — aunque no a la mayoría - el acceso a más productos de mayor calidad y servicios a mejores precios. Pero este no es el caso para los bienes básicos, incluyendo la comida, la ropa y los servicios públicos (Acosta, 2014: 17). El comercio total de México con Estados Unidos creció 4.4 veces durante el mismo periodo, durante el cual las exportaciones crecieron 5.6 veces y las importaciones 3.4 veces. Mucho del crecimiento exportador de México beneficia a Estados Unidos. La representante comercial que negoció el TLCAN, Carla Hills, informó que «por cada dólar que México gana en exportaciones, gasta 50 centavos en productos estadounidenses» (citado en Acosta, 2014:20).

Hay mediciones del desarrollo económico que se hacen para cada nación en cuanto al producto interno bruto (PIB) y al PIB per cápita. De 1994 a 2012, Canadá declinó en su rango mundial por tamaño del PIB del lugar 7 a 11, al igual que México cayó del lugar 10 al 14, mientras que Estados Unidos siguió en el primer lugar. En términos per cápita, la imagen que surge es diferente y favorece más a Canadá. Su rango mundial en ingreso per cápita subió de 21 a 9, mientras que México cayó de 53 a 61 y Estados Unidos cayó del 9 a 10.

Volviendo la mirada hacia la agricultura, tenemos que tanto las importaciones como las exportaciones crecieron en los tres países, pero los patrones comerciales de cada par de países estuvieron ampliamente diferenciados. Estados Unidos desarrolló una relación de comercio agrícola muy fuerte con cada uno de sus vecinos. El comercio entre canadienses y mexicanos ha sido comparativamente menor, sin embargo las importacio- 
nes de México desde Canadá han ido creciendo (véanse las gráficas 1 y 2). La principal relación comercial agrícola de México es claramente con Estados Unidos y muestra un déficit desde principios de los años noventa -excepto en 1995 después de la devaluación del peso en diciembre de 1994-, lo cual forzó a México a reducir sus importaciones. Curiosamente, la crisis global de inflación alimentaria de 2007-2008 no se reflejó en una caída de las importaciones estadounidenses desde México. Estas tendencias diferenciadas tienen que ver con dos asuntos distintos pero combinados. Primero, las importaciones de México son fundamentalmente de productos básicos (véanse las gráficas más abajo), que constituyen una gran proporción de la ingesta calórica ( $>40$ por ciento) y repercute desproporcionadamente hacia la población de más bajos ingresos o medios. Segundo, las importaciones de Estados Unidos desde México son primordialmente frutas y verduras, las que constituyen una magra porción de la ingesta alimentaria ( 2 por ciento de cada rubro), que las consumen principalmente las clases más acomodadas. Por tal motivo se clasifica aquí la fruta como alimento de lujo, sin desmedro de su alto contenido nutritivo. Las agudas desigualdades de cada uno de estos países vecinos complican los efectos: la tasa oficial de pobreza, que por definición incluye inseguridad alimentaria, es de menos de 15 por ciento en Estados Unidos mientras que en México es de 45.5 por ciento. En este contexto, inseguridad alimentaria significa que para cada punto porcentual que aumente el precio de los alimentos habrá una caída de 0.75 por ciento en gastos alimentarios (Von Braun, 2007).

La relación comercial entre Canadá y Estados Unidos también se ha consolidado con el TLCAN. Sin embargo, en contraste con la relación México-Estados Unidos, Canadá ha cambiado su posición levemente deficitaria antes del TLCAN a una fuertemente superavitaria con Estados Unidos; lo inverso de México (véase la gráfica 1). Esta relación replica el tipo de relación que tiene Estados Unidos con México, pero a la inversa: este último exporta sobre todo productos de lujo a Canadá e importa productos básicos de este país. En consecuencia, otro curioso contraste es que las importaciones de Estados Unidos desde Canadá 
cayeron agudamente durante la crisis de 2007-2008, indicando que el contenido era principalmente de alimentos básicos, pero las importaciones de Canadá desde Estados Unidos no sufrieron mayor cambio, pues éstas constituyen sobre todo frutas y verduras que consumen las clases de mayores ingresos. A partir de este criterio, entonces, Canadá parece haberse beneficiado del TLCAN. Esto lo confirma la subida en el rango mundial de ingreso per cápita, mientras que los rangos de México y Estados Unidos se fueron a la baja, como lo vimos más arriba.

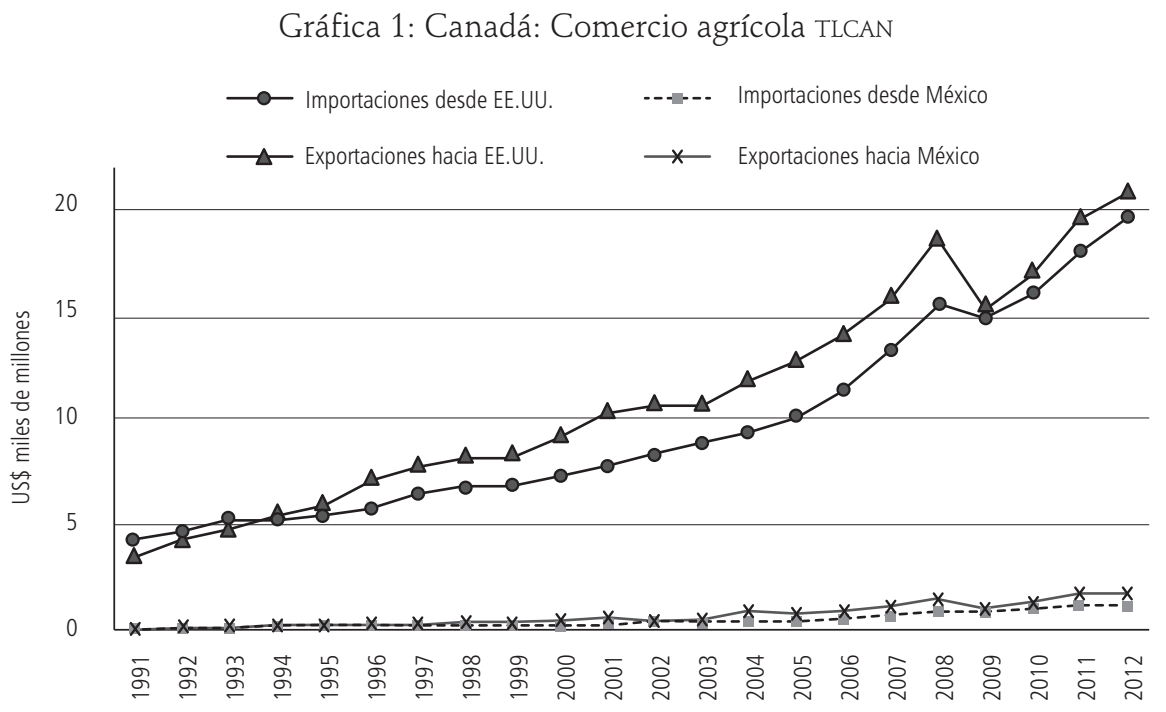

Fuente: Elaboración propia con base en datos de producción alimentaria doméstica de FAOSTAT, disponibles en: http://faostat.fao.org/site/609/DesktopDefault.aspx?PageID=609\#ancor (consultado el enero 4 de 2014).

Si observamos la naturaleza de las importaciones y exportaciones agrícolas de estos países en términos más generales, sin limitarnos a las relaciones comerciales intra-TLCAN, de nuevo encontramos que, en términos de precios en dólares, las principales importaciones agroalimentarias de Estados Unidos son principalmente de lujo; en este caso, bebidas alcohólicas, carnes de res y ternera, café y otras materias primas para ser procesadas. El patrón de Canadá fue similar, siendo sus mayo- 
res importaciones agroalimentarias por valor las bebidas alcohólicas, materias primas crudas, preparados de chocolate y alimento para mascotas (Pechlaner y Otero, 2010). En México, sin embargo, el mayor crecimiento en su dependencia alimentaria ha sido en lo que llamamos alimentos básicos, incluidos los granos y cereales (Otero, Pechlaner y Gürcan, 2013). Pero México también ha desarrollado una dependencia en la importación de alimentos de lujo como carnes, especialmente pollo y vino, como se verá más delante.

\section{Gráfica 2: México: Comercio agrícola TLCAN}

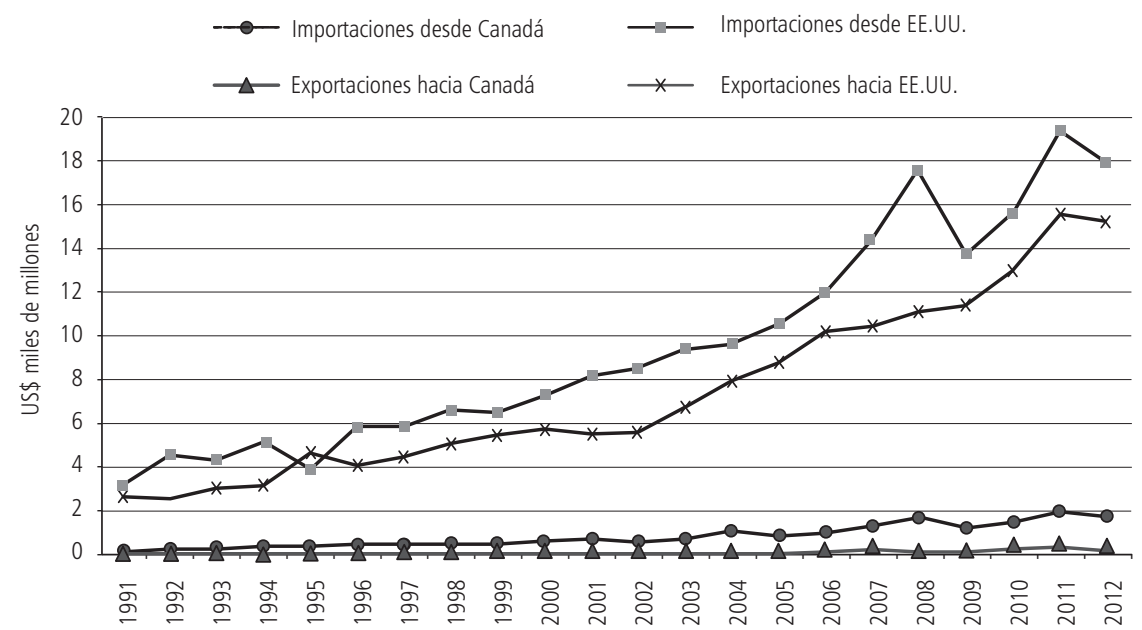

Fuente: Elaboración propia con base en datos de producción alimentaria doméstica de FAOSTAT, disponibles en: http://faostat.fao.org/site/609/DesktopDefault.aspx?PageID=609\#ancor (consultado el enero 4 de 2014).

En el contexto de la seguridad alimentaria, la dependencia de las importaciones empuja al país importador a internalizar el precio mundial de una mercancía. Para países con una larga tradición agroexportadora como Canadá y Estados Unidos, este tema por sí mismo no es de gran preocupación sobre cómo repercuten los precios internos por dos razones principales: la primera es que estas naciones han estado articuladas a los mercados mundiales por décadas, y siempre han ejer- 
cido algún grado de proteccionismo u otras políticas de apoyo a sus sectores agrícolas (por ejemplo, el azúcar en Estados Unidos y lácteos en Canadá); la segunda, es que esos países también tienden a ser los que fijan los precios mundiales. Pero la nueva dependencia alimentaria de países como México, cuyos productores y consumidores se habían beneficiado de la protección estatal contra la volatilidad de los precios, ha introducido una considerable vulnerabilidad alimentaria para su población al sujetarla a los precios mundiales. Cuando esta dependencia se da respecto a un alimento básico, los efectos pueden ser graves para la gente de bajos ingresos y medios, quienes necesariamente gastan una mayor proporción en alimentos. En la región del TLCAN, dicha población se encuentra ubicada sobre todo en México.

Proponemos una medida de la dependencia alimentaria a partir de que las importaciones excedan 20 por ciento de la oferta local de cualquier mercancía. Puesto que la comida tiene un fuerte componente cultural, hemos hecho una investigación inductiva sobre cuáles son las cinco fuentes principales de alimentos para cada país del TLCAN y estimamos sus niveles de dependencia antes y después del giro neoliberal comparando 1985 y 2007 (Otero, Pechlaner y Gürcan, 2013). En el cuadro 1 refinamos nuestro análisis mostrando los cambios de la dependencia basados en las fuentes alimentarias que constituyen 80 por ciento de la dieta de cada nación. El número menor de cultivos resaltado en cursivas indica aquellos cultivos que constituyen 50 por ciento de la dieta del país, empezando con el mayor contribuidor a la ingesta calórica.

Lo primero que podemos observar en el cuadro 1 es la increíble diversidad de la dieta canadiense, comparada con la de México y Estados Unidos. Si bien, tal variedad decreció marginalmente de 1985 a 2007, todavía era significativa. También podemos observar que la dependencia no creció notablemente en Canadá en términos del número de cultivos, aunque tiene una dependencia considerable en ambos años. De los cultivos que constituyeron hasta 80 por ciento de la oferta alimentaria canadiense, el país tuvo una dependencia de las importaciones de 12 
por ciento en 1985 y 14 por ciento en $2007 .{ }^{1}$ La mayoría de estos cultivos no han sido muy significativos en cuanto a la contribución a la dieta canadiense, aunque lo fueron algo más en 2007 que en 1985. En 1985, ninguno de los alimentos en que el país tenía dependencia daba cuenta siquiera de 2 por ciento de la oferta alimentaria total, y muchos estaban muy por debajo de eso. Para 2007, vemos que la dependencia importadora fue mayor en los alimentos más importantes, pero aun así sólo tres de ellos contribuyeron con más de 3 por ciento a la oferta alimentaria total (el maíz con 3.32 por ciento, el aceite de mostaza con 9.75 por ciento y el aceite de soya con 3.34 por ciento). Si calculamos cuánto aportan estos productos con dependencia a la ingesta total vemos que hubo algún cambio de 1985 a 2007. Si bien la dependencia era de 10.99 por ciento en 1985 , subió a 31.9 por ciento en 2007, un incremento notable de 20.91 puntos porcentuales o casi el triple.

La dieta de Estados Unidos ha sido consistentemente menos diversa que la canadiense, con un número mucho menor de cultivos que dan cuenta de 50 por ciento o inclusive de 80 por ciento de la ingesta total. El país ha incrementado su dependencia en el periodo bajo consideración apenas en un cultivo adicional. Si bien siguió siendo dependiente de la importación de azúcar, en 2007 el país también lo era en la importación de arroz (que era de 25 por ciento). Nuevamente, observando el cambio de dependencia para la oferta alimentaria total en su conjunto, vemos que Estados Unidos tuvo una dependencia mayor a 20 por ciento en 8.5 por ciento de su oferta en 1985 (en azúcar) y aumentó a 11.2 por ciento para 2007, con la adición del arroz — un aumento de dependencia alimentaria de apenas 2.7 puntos porcentuales - . Hay que aclarar que el azúcar ha sido importada por los países industrializados por siglos, y se le somete a un procesamiento ulterior en dichos países, por tanto, el azúcar es una exportación primaria

\footnotetext{
${ }^{1}$ Cabe hacer notar que el azúcar tiene un papel peculiar en Canadá, pues la importa sin refinar, la procesa y refina, y hasta tiene excedentes para reexportarla. Por ajustarse a los patrones tradicionales de importación de productos primarios por parte de un país «central» en el sistema-mundo para su procesamiento industrial, hemos excluido el azúcar de las fuentes alimentarias con dependencia (Otero et al., 2013).
} 
típica de los países en desarrollo. A pesar de que ha llegado a constituir una de las principales fuentes calóricas, dada su relativa abundancia en el mercado mundial, difícilmente se le puede considerar como algo distinto a un alimento de lujo (Mintz, 1985), cuya dependencia de las importaciones difícilmente pone en amenaza la nutrición del pueblo. ${ }^{2}$

México ha sido todavía menos diverso en su dieta que Estados Unidos, aunque vemos que aumentó después del TLCAN, lo cual sería más consistente con la expectativa de la liberalización comercial en agricultura de lo que observamos en Estados Unidos. La dependencia alimentaria de México creció notablemente en comparación con los otros dos países. Por ejemplo, en 1985 era dependiente de dos cultivos de los que contribuían con 80 por ciento de su ingesta calórica total, mientras para 2007 el número de cultivos aumentó a siete, lo cual es notable, y el profundo descenso del país hacia la dependencia alimentaria resalta cuando observamos el resumen de las estadísticas de dependencia en 1985, que equivalía a 8.49 por ciento de la oferta alimentaria. En contraste, para 2007 los siete alimentos en los cuales México tenía dependencia constituían un enorme 56.29 por ciento de la dieta promedio diaria del país (véase el cuadro 1). En conclusión, podemos decir que la liberalización comercial ha tenido un efecto marginal o modesto en Canadá y Estados Unidos, pero ha sido profundo en la dependencia alimentaria de México. Dada la mayor repercusión que tiene la inflación de precios alimentarios sobre la gente de ingresos bajos y medios, vemos claramente que esta dependencia de los precios mundiales tendrá un efecto negativo desproporcionado en este país en vías de desarrollo.

${ }^{2}$ El azúcar no desempeña el mismo papel comercial o manufacturero en Estados Unidos y Canadá, país que ha eliminado casi todo el proteccionismo que alguna vez promovió la producción de remolacha azucarera en algunas provincias. Estados Unidos, por contraste, sigue protegiendo fuertemente su industria azucarera ubicada en los estados de Luisiana, Florida y Hawaii, lo cual indirectamente también posibilita la producción de remolacha en el mediooeste. La misma política proteccionista constituyó la condición para la factibilidad económica de producir jarabe de maíz de alta fructosa a finales de los años setenta, con el cual se endulzan una infinidad de productos, sobre todo los refrescos. Aun así, el azúcar no es barata en Estados Unidos; es más barata en Canadá y México, al grado de que algunas empresas de confitería se han reubicado en estos países (Otero y Flora, 2009). 
Cuadro 1. Niveles de dependencia en los alimentos que constituyen 80 por ciento de la oferta alimentaria (kcal/cápita/día) (cantidad importada/oferta local)

\begin{tabular}{|c|c|c|c|c|}
\hline \multicolumn{3}{|c|}{1985} & \multicolumn{2}{|c|}{2007} \\
\hline PAÍS & ALIMENTOS PRINCIPALES & $\begin{array}{c}\text { IMPORTACIONES > } \\
20 \% \%^{* *}\end{array}$ & ALIMENTOS PRINCIPALES* & $\begin{array}{l}\text { IMPORTACIONES } \\
>20 \% * *\end{array}$ \\
\hline CANADÁ & $\begin{array}{l}\text { Trigo, leche aceite de } \\
\text { mostaza, grasas } \\
\text { animales, carne de } \\
\text { puerco, papas, car- } \\
\text { ne de res; } \\
\text { cerveza, carne de } \\
\text { pollo, aceite de } \\
\text { soya, mantequilla, } \\
\text { otras verduras, } \\
\text { huevos, arroz, } \\
\text { aceite de maíz, } \\
\text { manzanas, crema, } \\
\text { naranjas, manda- } \\
\text { rinas, maíz, nue- } \\
\text { ces, otras frutas, } \\
\text { tomate, bebidas } \\
\text { fermentadas }\end{array}$ & $\begin{array}{l}\text { Nueces (104), } \\
\text { otros edulco- } \\
\text { rantes (102), } \\
\text { arroz (100), ca- } \\
\text { cahuates (100), } \\
\text { naranjas (100), } \\
\text { mandarinas } \\
\text { (100), plátanos } \\
(100) \text {, otras fru- } \\
\text { tas (81), toron- } \\
\text { jas (79), otras } \\
\text { verduras (47), } \\
\text { manzanas (40), } \\
\text { aceite de maíz } \\
\text { (34), tomates } \\
\text { (33) }\end{array}$ & $\begin{array}{l}\text { Trigo, aceite de mos- } \\
\text { taza, leche, carne de } \\
\text { pollo, grasas anima- } \\
\text { les, carne de puerco, } \\
\text { aceite de soya, maí, } \\
\text { papas, carne de res, } \\
\text { arroz, otros edulco- } \\
\text { rantes, cerveza, } \\
\text { otras verduras, } \\
\text { mantequilla, otras } \\
\text { legumbres, crema, } \\
\text { huevos, cacahua- } \\
\text { tes, aceite de maíz, } \\
\text { otras frutas, nue- } \\
\text { ces, aceite de oliva, } \\
\text { manzanas, pláta- } \\
\text { nos }\end{array}$ & $\begin{array}{l}\text { Arroz (141), caca- } \\
\text { huates (120), nue- } \\
\text { ces (104), aceite } \\
\text { de oliva (103), } \\
\text { otras frutas (102), } \\
\text { otros edulcorantes } \\
\text { (100), plátanos } \\
\text { (100), otras verdu- } \\
\text { ras (68), manza- } \\
\text { nas (53), aceite de } \\
\text { maíz (40), aceite } \\
\text { de soya (35), acei- } \\
\text { te de canola (25), } \\
\text { carne de res } \\
\text { (21\%), maíz (20) }\end{array}$ \\
\hline MÉXICO & $\begin{array}{l}\text { Maíz, azúcar, tri- } \\
\text { go, leche, carne de } \\
\text { puerco, frijoles, } \\
\text { aceite de girasol, } \\
\text { aceite de soya }\end{array}$ & $\begin{array}{l}\text { Leche (24), } \\
\text { aceite de girasol } \\
(21)\end{array}$ & $\begin{array}{l}\text { Maiz, azúcar, trigo, } \\
\text { carne de puerco, } \\
\text { aceite de soya, car- } \\
\text { ne de pollo, frijoles, } \\
\text { huevos, arroz, car- } \\
\text { ne de res, aceite de } \\
\text { palma }\end{array}$ & $\begin{array}{l}\text { Aceite de palma } \\
(86 \%) \text {, arroz } \\
(76 \%) \text {, trigo (58\%), } \\
\text { aceite de soya } \\
(33 \%), \text { carne de } \\
\text { puerco }(29 \%) \text {, } \\
\text { maíz (28\%), leche } \\
(22 \%)\end{array}$ \\
\hline $\begin{array}{l}\text { ESTADOS } \\
\text { UNIDOS }\end{array}$ & $\begin{array}{l}\text { Trigo, aceite de } \\
\text { soya, leche, azúcar, } \\
\text { otros edulcoran- } \\
\text { tes, carne de res, } \\
\text { carne de puerco, } \\
\text { cerveza, grasas } \\
\text { animales, papas, } \\
\text { maíz }\end{array}$ & Azúcar (36) & $\begin{array}{l}\text { Trigo, aceite de soya, } \\
\text { leche, azúcar, otros } \\
\text { edulcorantes, carne } \\
\text { de pollo, carne de } \\
\text { puerco, carne de } \\
\text { res, cerveza, maíz, } \\
\text { papas, arroz, grasas } \\
\text { animales }\end{array}$ & $\begin{array}{l}\text { Arroz (25) } \\
\text { azúcar (22) }\end{array}$ \\
\hline
\end{tabular}

Notas:

*Ordenados por su rango en cada país. Los datos en cursivas incluyen fuentes alimentarias que dan cuenta de 48 a 50 por ciento de la oferta alimentaria total.

**Ordenados por su índice de dependencia alimentaria. Los que aparecen en cursivas están dentro de 50 por ciento que constituyen la mayor fuente de alimentos.

Fuente: United Nations Commodity Trade Statistics, United Nations Statistics Division. 


\section{LA DIETA NEOLIBERAL EN LA REGIÓN DEL TLCAN}

El análisis de datos que sigue muestra cómo ha evolucionado la dieta neoliberal en los tres países miembros. Si bien nuestro supuesto es que la dieta neoliberal emana primordialmente de Estados Unidos y se ha vuelto hegemónica durante el neoliberalismo, nuestra meta aquí es determinar cómo se ha expresado en los tres países de la región. Empezamos con una evaluación básica del consumo alimentario promedio diario per cápita, donde usamos los datos sobre «oferta alimentaria» (es decir, existencias más producción doméstica, más importaciones, menos exportaciones en un año determinado) como representante del consumo.

El primer y principal punto que hay que resaltar es que el país menos desarrollado en esta asociación regional, México, experimentó el mayor crecimiento en su ingesta alimentaria antes de unirse al TLCAN. De hecho, para finales de los años setenta y principios de los ochenta del siglo $\mathrm{xx}$, la ingesta alimentaria per cápita de México sobrepasaba la de Canadá y casi alcanzaba a la de Estados Unidos. Después del giro neoliberal en México, sin embargo, el consumo alimentario declinó o se estancó en el país (véanse las gráficas 3 y 4), mientras que sus vecinos desarrollados experimentaron incrementos sustanciales en su ingesta alimentaria promedio.

La gráfica 4 muestra cómo el aumento o disminución del consumo alimentario per cápita ha evolucionado en diferentes periodos entre 1961 y 2009. Lo hemos dividido para poder diferenciar la era que precede el vuelco neoliberal (1961-1981) de la era posterior. La anterior estuvo marcada por el hecho de que la producción de alimentos estaba basada, principalmente, en el mercado interno con muy poco comercio agrícola internacional. En contraste, el comercio alimentario se volvió muy importante en los tiempos posteriores, sobre todo después del inicio del TLCAN en 1994. Al observar el cálculo de los datos sobre consumo alimentario abajo, debemos tomar en cuenta que la ingesta calórica per cápita de México se inició con una base mucho más baja en 1961, de tal manera que el crecimiento global entre 1961 y 2009 fue relativamente mayor a los incrementos de sus países vecinos. Pero el punto 
central aquí es que los aumentos principales se lograron antes del vuelco neoliberal a mediados de los ochenta y antes del TLCAN (1994). Mostramos esto en la gráfica 4 mediante el simple cálculo de las tasas de aumento de ingesta alimentaria en los periodos especificados, dividiendo las calorías ingeridas en el año más reciente por aquellas del año anterior. Las tasas resultantes indican cuánto creció o disminuyó el consumo alimentario de un periodo al otro. Después de 1981, la ingesta calórica de hecho decreció en ambos (1991/1981 y 2009/1981), mientras que la ingesta en Canadá y Estados Unidos creció.

\section{Gráfica 3: TLCAN: Oferta alimentaria total (kcal/cápita/día)}

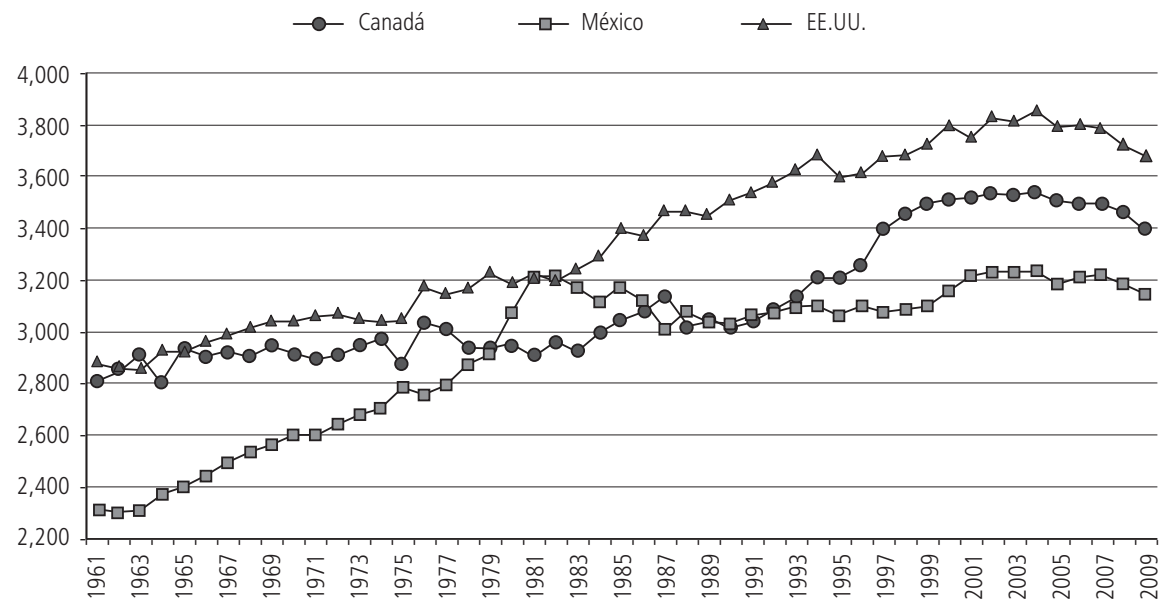

Fuente: Elaboración propia con base en datos de producción alimentaria doméstica de FAOSTAT, disponibles en: http://faostat.fao.org/site/609/DesktopDefault.aspx?PageID=609\# ancor (consultado el enero 4 de 2014).

Sin embargo, el consumo per cápita de alimentos es sólo un aspecto de la dieta neoliberal. Otro aspecto es el creciente papel de las carnes y más complejo de las frutas y verduras frescas, que se complica tanto por la industrialización de las dietas como por la creciente dinámica clasista en el consumo de productos frescos. En efecto, encontramos que los componentes de la dieta neoliberal cambian diferenciadamente, dependiendo 
de qué clase socioeconómica tiene el acceso primordial a qué tipo de alimentos en particular. Los cambios en los patrones de consumo de los alimentos «de lujo» como la carne, fruta, verdura y vino, por ejemplo, serán diferentes de los cambios en los patrones de consumo de alimentos «básicos», tales como los granos. Pongamos como ejemplo la carne de res.

Gráfica 4: TLCAN: Tasas de aumento en la oferta alimentaria, 1961-2009

Canadá $\square$ México $\square$ EE.UU.

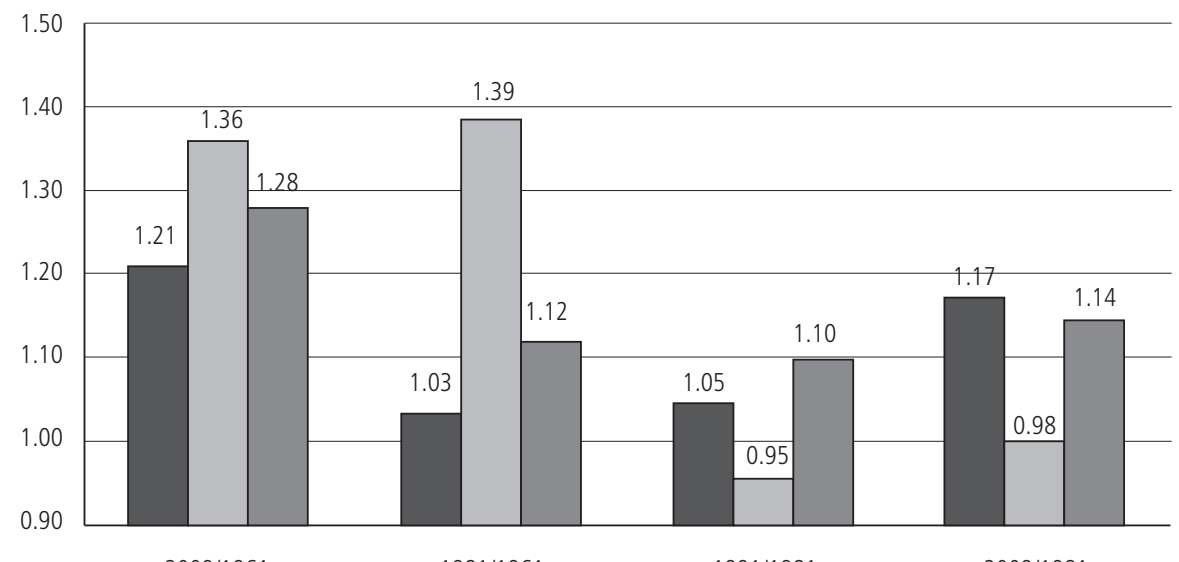

2009/1961

$1981 / 1961$

$1991 / 1981$

2009/1981

Fuente: Elaboración propia con base en datos de producción alimentaria doméstica de FAOSTAT, disponibles en: http://faostat.fao.org/site/609/DesktopDefault.aspx?PageID=609\# ancor (consultado el enero 4 de 2014).

Una tendencia general tanto en Canadá como en Estados Unidos es que el consumo per cápita de res ha disminuido, especialmente después de la crisis del fordismo a finales de los años setenta. Nuestra interpretación de esta tendencia es que, si bien las clases medias, y tal vez inclusive las de bajos ingresos, habían tenido acceso a la carne de res en esos países, después de 1976 tuvieron mayores dificultades para comprarla. Además, por esas fechas surgieron las preocupaciones por los efectos sobre la salubridad que podían ocasionar las carnes rojas, de tal forma que mucha gente las cambió 
por carne de pollo — que también es más barata que la de res-. En México, sin embargo, las clases medias y altas fueron las principales consumidoras de la dieta basada en carne, leche y trigo de Estados Unidos (Otero y Pechlaner, 2014). Entonces, como lo indica la gráfica 5, tanto Canadá como Estados Unidos experimentaron el crecimiento en el consumo de carne de res antes de 1976, después de lo cual se dio sobre todo una disminución. México empezó desde una base considerablemente más baja que sus dos vecinos, pero experimentó aumentos sustanciales en el consumo de carne de res desde 1961, con leves bajas en periodos inflacionarios, como a principios de los años setenta. Los niveles absolutos de consumo de carne de res per cápita en México siguen estando muy por debajo de los de sus vecinos, indicando muy posiblemente que sus consumidores principales son las clases medias-altas y altas. Para 2009, el promedio mexicano de consumo calórico proveniente de la carne de res era apenas de 57 kilocalorías diarias, mientras que el canadiense era de 95 y el estadounidense era de 110. Sin embargo, considerando las más profundas desigualdades de clase en México, y el hecho de que las consumidoras de carne de res son primordialmente las clases medias-altas y altas (mucho más reducidas en tamaño), los niveles de consumo per cápita son por lo menos iguales a los de las clases equivalentes en Canadá o Estados Unidos.

Cada vez hay más gente en los países del TLCAN que consume carne de pollo, la cual aparece en un creciente número de preparaciones de alimentos industrializados como las milanesas de pollo. Como lo ha planteado Michael Pollan (2006), el pollo acumula maíz sobre maíz, el producto más subsidiado en Estados Unidos. Desde los años setenta, los drásticos aumentos en la producción de pollo han estado basados sobre todo en Estados Unidos. La producción también aumentó en México desde los años noventa, aunque aún sigue muy por debajo de la estadounidense. Como se mencionó, además de las preocupaciones por el costo, para los años ochenta las preocupaciones por la sanidad en Estados Unidos en torno a las carnes rojas facilitaron aún más la revolución del pollo (Schwartzman, 2013). Este cambio dietético se ha dado a pesar del hecho de que el pollo criado en condiciones industriales, altamente confinadas en el espacio, tiene tantas grasas saturadas que 
ponen en duda su carne «supuestamente más saludable» (Winson, 2013: 145). Como lo muestra la gráfica 6, todos los países del TlCAN han experimentado aumentos per cápita en el consumo de carne de pollo, pero en una escala mucho mayor en los países desarrollados, dado el mayor poder adquisitivo de las clases trabajadoras con ingresos medios.

\section{Gráfica 5: TLCAN: Oferta de carne de res}

(kcal/cápita/día)

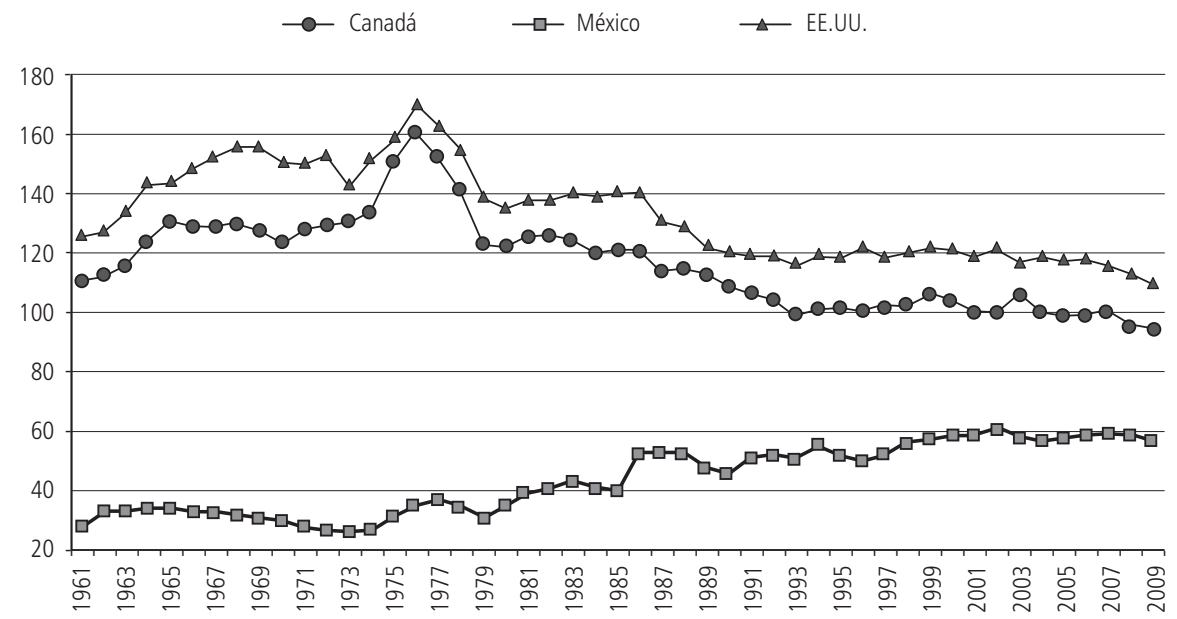

Fuente: Elaboración propia con base en datos de producción alimentaria doméstica de FAOSTAT, disponibles en: http://faostat.fao.org/site/609/DesktopDefault.aspx?PageID=609\#ancor (consultado el enero 4 de 2014).

Como también lo muestra la gráfica 6, a pesar de los precios bajos, el consumo per cápita de pollo declinó en Canadá y Estados Unidos después de la crisis de 2007-2008, aunque siguió en leve ascenso en México. Nuestra interpretación clasista de estas tendencias es la siguiente: el consumo de pollo había sido ampliamente adoptado por las clases trabajadoras de ingresos bajos y medios en Canadá y Estados Unidos, las cuales tuvieron que reducir el consumo de este alimento, relativamente de lujo, con la crisis. A la inversa, en México fueron principalmente las clases medias y altas las que habían aumen- 
tado su ingesta de pollo, y no se vieron en la necesidad de reducir su consumo puesto que sus gastos en comida representan una proporción más reducida en sus presupuestos familiares. Para cuando llegó la crisis, en efecto, la oferta de carne de pollo había aumentado sustancialmente en México, tanto por la vía de las importaciones desde Estados Unidos, como por la producción doméstica usando maíz y harina de soya importados del mismo país (Schwartzman, 2013; Constance et al., 2013). En contraste con la carne de res, podríamos afirmar que la carne de pollo se ha convertido en la principal carne neoliberal, dado que su consumo se ha incrementado en todo el periodo desde 1961, pero más drásticamente después de 1990. La tasa de crecimiento del consumo de pollo en México ha sido más rápida, pero se inició desde una base mucho más baja. Para 2009, la ingesta promedio per cápita diaria de carne de pollo en kilocalorías fue la siguiente: Estados Unidos, 193; Canadá, 144; y México, 110. Hay, pues, un cierto nivel de convergencia en este aspecto.

\section{Gráfica 6: TLCAN: Oferta de carne de pollo} (kcal/cápita/día)

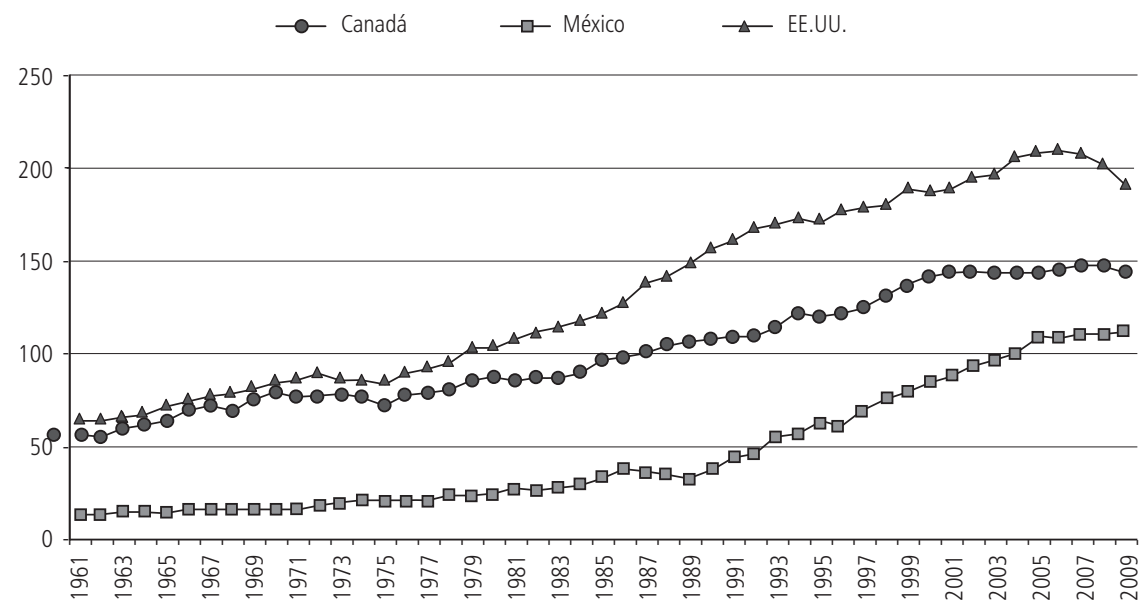

Fuente: Elaboración propia con base en datos de producción alimentaria doméstica de FAOSTAT, disponibles en: http://faostat.fao.org/site/609/DesktopDefault.aspx?PageID=609\# ancor (consultado el enero 4 de 2014). 
Otro elemento que frecuentemente se articula respecto a la cambiante división internacional del trabajo en la agricultura ha sido la producción y exportación de frutas y verduras frescas por parte de los países en desarrollo para los consumidores afluentes de los países desarrollados. Nagatada (2006), por ejemplo, conduce una investigación extensa del comercio global de frutas y verduras y concluye que en efecto se ha expandido para convertirse en la "parte más significativa del sistema agroalimentario global bajo el tercer régimen alimentario» (2006: 38). Al mismo tiempo, argumenta que la diferenciación Norte-Sur es en realidad más matizada, hasta se podría caracterizar como multipolarizada, puesto que el crecimiento económico en los países en desarrollo, por ejemplo, acelera su importación de frutas y verduras. No obstante, Nagatada documenta un aumento recíproco significativo en el «flujo TLCAN» de verduras entre los tres países $(2006: 39)$.

\section{Gráfica 7: TLCAN: Oferta de verduras} (kcal/cápita/día)

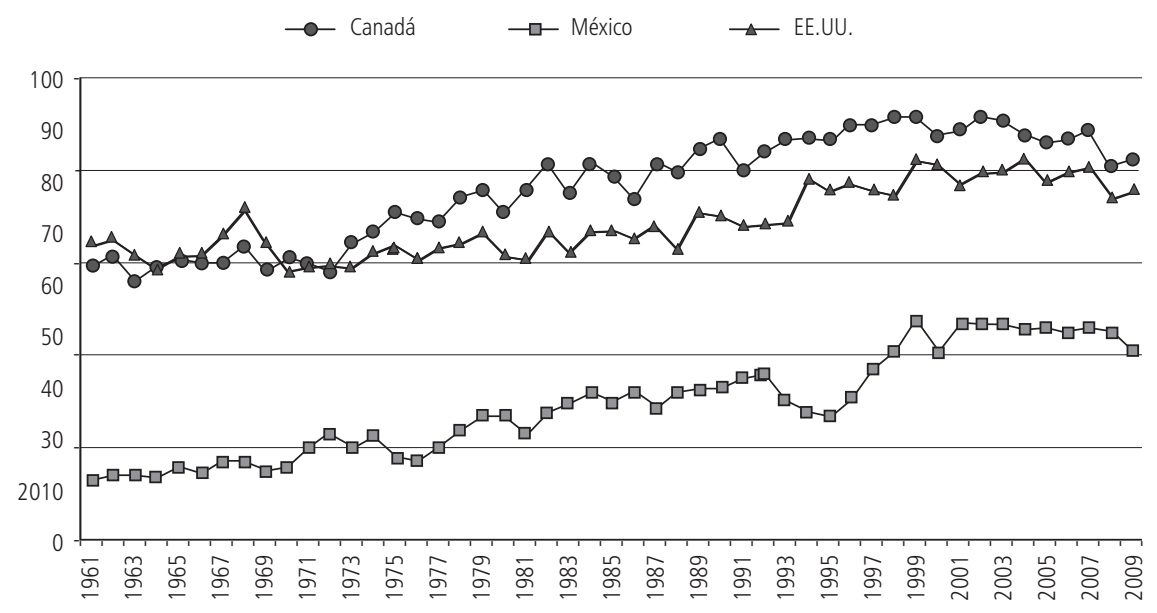

Fuente: Elaboración propia con base en datos de producción alimentaria doméstica de FAOSTAT, disponibles en: http://faostat.fao.org/site/609/DesktopDefault.aspx?PageID=609\#ancor (consultado el enero 4 de 2014). 
Algo que puede sorprender es que el consumo de verduras frescas en México ha crecido desde los años setenta, particularmente desde el inicio del TLCAN, como se puede observar en la gráfica 7. Los cambios han sido modestos en Canadá y Estados Unidos, pero siempre desde bases iniciales superiores. Medido como porcentaje de la ingesta alimentaria total, el consumo mexicano de verduras se inició apenas en 0.50 por ciento en 1961 y subió a 1.3 por ciento en 2009. En contraste, las cifras de los países vecinos fueron de alrededor de 2 por ciento para todo el periodo, y Canadá superó a Estados Unidos en 1972. Entonces, si bien hay una convergencia hacia arriba, México sigue estando muy por debajo de sus vecinos en la ingesta de verduras frescas como porcentaje de su ingesta total.

Observando el consumo de fruta en la gráfica 8 , vemos que a mediados de los años sesenta, principios de los setenta y de los ochenta, el consumo per cápita de fruta era mayor que el de Canadá, aunque más bajo que el de Estados Unidos (exceptuando 1984). Sin embargo, para finales del largo periodo analizado aquí (1961-2009), sólo Canadá podía sostener un alto consumo calórico a partir de la fruta, con algunas importaciones desde México. En contraste, la ingesta promedio de fruta en México experimentó fuertes fluctuaciones y rara vez superó su máximo alcanzado anterior al TLCAN de 1984, superándola apenas en 2001 y en 2003. Sospechamos que los modestos aumentos en el consumo de fruta en México en los últimos años del periodo bajo análisis se deben, primordialmente, a la capacidad adquisitiva de las clases de altos ingresos. De hecho, Humberto González (2013) ha demostrado que el aumento de la exportación de frutas y verduras desde México las ha hecho más caras en su mercado local, de tal manera que pocos pueden permitirse comprarlas como antaño. Podemos conjeturar que el aumento del consumo que observamos en la gráfica 8 denota un aumento del consumo de frutas y verduras de las clases más acomodadas. 
Gráfica 8: TLCAN: Oferta de frutas

(kcal/cápita/día)

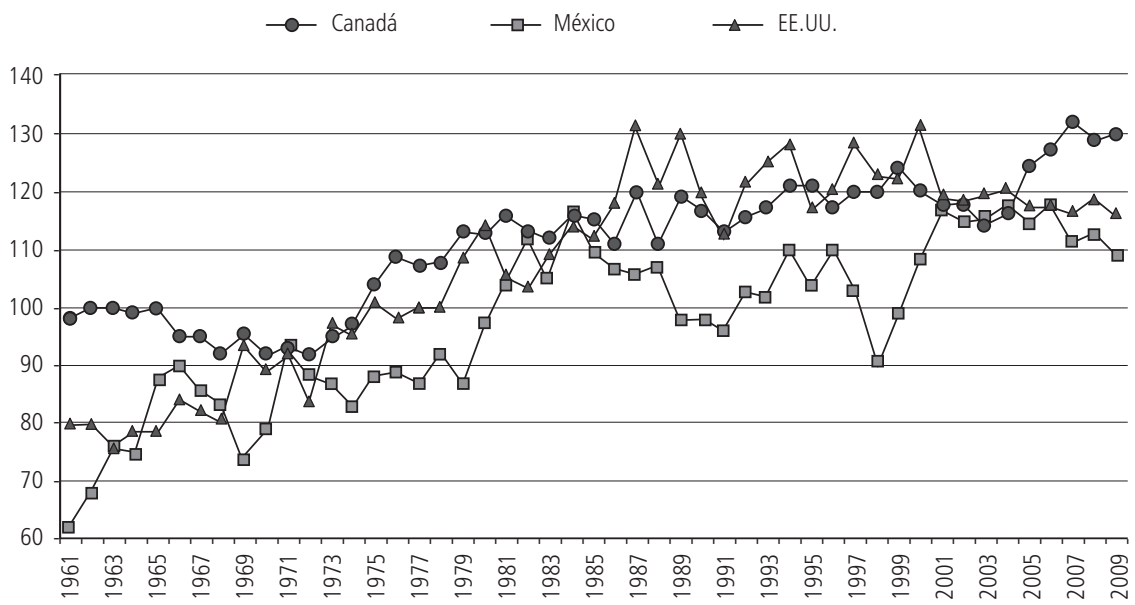

Fuente: Elaboración propia con base en datos de producción alimentaria doméstica de FAOSTAT, disponibles en: http://faostat.fao.org/site/609/DesktopDefault.aspx?PageID=609\#ancor (consultado el enero 4 de 2014).

\section{CONCLUSIÓN}

Como resultado del TLCAN, efectivamente hemos observado el crecimiento del comercio agrícola en los tres países, tal como se había anticipado por la liberalización comercial. Pero también hay una marcada divergencia en la naturaleza del comercio agrícola entre sus socios, sobre todo, desde la perspectiva de la dependencia alimentaria del país menos desarrollado. Las consecuencias sociales de esta dependencia son profundas cuando aumentan los precios, como quedó claro en 2007-2008, con inflación renovada en 2011-2012. Todas las indicaciones apuntan a que dicha vulnerabilidad tendrá consecuencias drásticas en el futuro, en la medida en que eventos climáticos, presiones demográficas y escasez de tierra empujen consistentemente los precios al alza en estos tiempos tan «interesantes». Ya hemos visto que desde 2011 el índice de precios alimentarios no ha caído por debajo del nivel anterior a la crisis; en efecto, en varios años han estado por encima de ello: 
229.9 por ciento en 2011; 213.3 en 2012; 209.8 por ciento en 2013, comparado con 201.4 por ciento en 2008 (todo respecto a 2007) (FAO, 2014). Por lo tanto, aunque hemos observado la anticipada convergencia en cuanto a flujos comerciales y patrones dietéticos en los tres países del TLCAN, si consideramos este comercio desde la perspectiva del bienestar humano, sólo nos cabe concluir que ha habido una significativa divergencia entre las experiencias de México en comparación con sus países vecinos más ricos. Lo anterior tiene también una diferenciación de clase al interior de cada país.

En relación con el contenido dietético, observamos una convergencia hacia los patrones estadounidenses. Aunque siguen las diferencias significativas entre los países del TLCAN — predecibles, dadas las diferencias en niveles de desarrollo entre México y sus dos socios-, hay evidencia también de que se da una convergencia diferenciada por clases sociales, siendo lo más notable el aumento en el consumo de carnes y frutas. En resumen, si bien el TLCAN ha producido divergencia en los indicadores de desarrollo socioeconómico, también ha facilitado una convergencia dietética con una marcada diferenciación clasista. Puesto que tal divergencia socioeconómica tiene repercusiones negativas sobre la desigualdad social y la seguridad alimentaria, y que la convergencia dietética tiene consecuencias de salubridad negativas, nuestro estudio de caso regional sugiere enfáticamente que el país menos desarrollado puede experimentar un doble efecto negativo por la liberalización comercial.

Ciertamente, el TLCAN ha tenido detractores. En efecto, como lo dijo en su momento Charlene Barshefsky, entonces representante comercial de Estados Unidos, mucha fricción al interior de los países y entre ellos hizo que el tratado fuese «algo controvertido en las tres naciones» (citada en Morton, 1999). No obstante lo anterior, la neorregulación, en general, y la liberalización comercial, en particular, siguen siendo ideales hegemónicos del neoliberalismo. De acuerdo con el ministro de Comercio canadiense, Ed Fast, por ejemplo, «el comercio libre y abierto es uno de los mejores creadores de empleos y es crítico para la prosperidad de largo plazo de Canadá» (Fekete, 2011). En la medida en que el TLCAN replique su dinámica en escala global, nuestra lectura 
de los resultados sugiere que la divergencia-y-convergencia-con-diferenciación-clasista presenta un desafío considerable para los supuestos beneficios de la liberalización comercial agrícola para los países menos desarrollados. En consecuencia, el Tratado ofrece un contrapunto a los imperativos de la política neorregulatoria, sobre todo los que se refieren a la liberalización agrícola. Tal como lo han propuesto los movimientos sociales de base en México, un programa centrado en la soberanía alimentaria que apoye a los pequeños campesinos y al campesinado empresarial sería lo más aconsejable, si el objetivo fuese promover la conservación de la biodiversidad vegetal y un desarrollo con equidad.

\section{REFERENCIAS}

Acosta Córdova, Carlos (2014), «La tierra prometida que nunca se alcanzó», Proceso, núm. 1940.

Althaus, Dudley (8 de julio de 2013), «How Mexico got so fat», Globalpost, en: http://www.globalpost.com/dispatch/news/regions/americas/mexico/130705/mexican-fattest-country-obesity.

Appendini, Kirsten (2014), «Reconstructing the Maize Market in Rural Mexico», Journal of Agrarian Change, vol. 14, no. 1, pp. 1-25.

Borras, Saturnino M. Jr., Ruth Hall, Ian Scoones, Ben White y Wendy Wolford (2011), «Towards a Better Understanding of Global Land Grabbing: an Editorial Introduction», The Journal of Peasant Studies, vol. 38, no. 1, pp. 209-216.

CNNexpansion (2014), «Grupo Modelo, s.A.B. de C.V.», en http://www.cnnexpansion.com/cnn2_empresa.php?id_opcion $=3 \& \operatorname{src}=B M V \& \operatorname{syma}=$ GMODELO\&Symb $=\mathrm{C}$ (consultado el 3 de enero de 2014).

Constance, Douglas, Francisco Martínez, Gilberto Aboites y Alessandro Bonanno (2012), «The Problems with Poultry Production and Processing», en Harvey, James (ed.), The Ethics and Economics of Agrifood Competition, Nueva York, Springer.

Darmon, Nicole y Adam Drewnowski (2008), «Does Social Class Predict Diet Quality?», American Journal of Clinical Nutrition, vol. 87, no. 5, pp. 1107-1117. 
Dixon, Jane (2009), «From the Imperial to the Empty Calorie: How Nutrition Relations Underpin Food Regime Transitions», Agriculture and Human Values, 26, pp. 321-333.

Drewnowski, Adam y Barry M. Popkin (1997), «The Nutrition Transition: New Trends in the Global Diet», Nutrition Reviews, vol. 55, no. 2, pp. 31-43. y Specter, S.E. (2004), «Poverty and Obesity: The Role of Energy Density and Energy Costs», American Journal of Clinical Nutrition, vol. 79, no. 1, pp. 6-16.

Fagan, Drew (1994), «Ministers Cite nafta Benefits Pact "Will Create Jobs",Kantor Says in Mexico City», The Globe and Mail, en http://search. proquest.com.proxy.lib.sfu.ca/docview/385184918?accountid=13800) (consultado el 8 de mayor de 2014).

Fenete, Jason (2011), «Free-trade frenzy», National Post, en http://search.proquest.com.proxy.lib.sfu.ca/docview/913019954?accountid=13800 (consultado el 8 de mayo de 2014).

Food and Agriculture Organization of the United Nations (FAo) »World Food Situation: FAo Food Price Index», en http://www.fao.org/worldfoodsituation/foodpricesindex/en/ (consultado el 13 de mayo de 2014).

Friedmann, Harriet (1992), «Distance and Durability: Shaky Foundations of the World Food Economy», Third World Quarterly, vol. 13, no. 2, pp. 371-383. (2005), «From Colonialism to Green Capitalism: Social Movements and Emergence of Food Regimes», Research in Rural Sociology and Development, vol. 11, pp. 227-264.

y Philip McMichael (1989), «Agriculture and the State System: The Rise and Decline of National Agricultures, 1870 to the Present», Sociologia Ruralis, vol. 29, no. 2, pp. 93-117.

González, Humberto (2013), «Especialización productiva y vulnerabilidad agroalimentaria en México», Comercio Exterior, vol. 63, no. 2, pp. 21-36, en http://revistacomercioexterior.com/rce/magazines/153/6/especializacion_ productiva.pdf (consultado el 17 de mayo de 2014).

Guthman, Julie (2011), Weighing In: Obesity, Food Justice, and the Limits of Capitalism, Berkeley, University of California Press.

LeE, Hedwig (2011), «Inequality as an Explanation for Obesity in the United States», Sociology Compass, vol. 5, no. 3, pp. 251-232.

Johnston, Joseé y Shyon Baumann (2010), Foodies: Democracy and Distinction in Gourmet Foodscape, Nueva York, Routledge. 
McMichael, Philip (1992), «Tensions Between National and International Control of the World Food Order: Contours of a New Food Regime», Sociological Perspectives, vol. 35, no. 2, pp. 343-365.

(2005), «Global Development and the Corporate Food Regime», Research in Rural Sociology and Development, vol. 11, pp. 269-303, en http:// www.agribusinessaccountability.org/pdfs/297_Global\%20Development\%20and\%20the\%20Corporate\%20Food\%20Regime.pdf (consultado el 18 de enero de 2006).

(2009a), «A Food Regime Analysis of the "World Food Crisis"», Agriculture and Human Values, vol. 26, no. 4, pp. 281-295.

(2009b), «A Food Regime Genealogy», The Journal of Peasant Studies, vol. 36, no. 1, pp. 139-169.

Mintz, Sidney (1985), Sweetness and Power: The Place of Sugar in Modern History, Nueva York, Penguin.

Morton, P. (1999), «Polishing the nafta Image Five-Year-Old Pact; Despite Growth in Trade, Misgivings Remain», National Post, en http://search.proquest.com.proxy.lib.sfu.ca/docview/329472617 ?accountid=13800 (consultado el 8 de mayo de 2014).

Nagatada, Takanayagi (2006), «Global Flows of Fruit and Vegetables in the Third Food Regime», Journal of Rural Community Studies, 102, pp. 25-41.

Otero, Gerardo (2014), La dieta neoliberal: Globalización y biotecnología en las Américas, México, Miguel Ángel Porrúa.

y Cornelia Butler Flora (2009), «Sweet Protectionism: State Policy and Employment in the Sugar Industries of the NAFTA Countries», en Juan M. Rivera, Scott Whiteford y Manuel Chávez (coords.), NAFTA and the Campesinos: The Impact of NAFTA on Small-Scale Agricultural Producers in Mexico and the Prospects for Change, Scranton and London, University of Scranton Press, pp. 63-88.

y Gabriela Pechlaner (2014), «La dieta estadounidense y la dependencia alimentaria en América Latina,» en Otero (2014), pp. 57-76.

, Gabriela Pechlaner y Efe Can Gürcan (2013), «The Political Economy of "Food Security" and Trade: Uneven and Combined Dependency», Rural Sociology, vol. 78, no. 3, pp. 263-289.

(en prensa), «The Neoliberal Diet: Fattening Profits and People», in Stephen Haymes, Maria Vidal de Haymes y Reuben Miller (eds.), Routledge Handbook of Poverty and the United States, Routledge. 
Pechlaner, Gabriela (2012), Corporate Crops: Biotechnology, Agriculture, and the Struggle for Control, Austin, University of Texas Press.

(2012), «Gmo Free America? Mendocino County and the Impact of Local Level Resistance to the Agricultural Biotechnology Paradigm», International Journal of the Sociology of Agriculture and Food, vol. 19, no. 3, pp. 445-464. y Gerardo Otero (2008), «The Third Food Regime: Neoliberal Globalism and Agricultural Biotechnology in North America», Sociologia Ruralis, vol. 48, no. 4, pp. 351-371.

y Gerardo Otero (2010), «Neoliberal Globalism and the Third Food Regime: Neoregulation and the New Division of Labor in North America», Rural Sociology, vol. 75, no. 2, pp. 179-208.

Pollan, Michael (2006), The Omnivore's Dilemma: a Natural History of Four Meals, Nueva York, Penguin Press.

Schwartzman, Kathleen (2013), The Chicken Trail: Following Workers, Migrants, and Corporations Across the Americas, Ithaca, Cornell University Press.

SNyder, Richard (2001), Politics After Neoliberalism: Reregulation in Mexico, Nueva York, Cambridge University Press.

Von Braun, Joachim (2007), The World Food Situation: New Driving Forces and Required Actions, Washington, DC: International Food Policy Research Institute.

Walsh-Dilley, Marygold (2009), «Localizing control: Mendocino County and the ban on GMOs», Agriculture and Human Values, vol. 26, no. 1-2, pp. 95 105.

Winson, Anthony (2013), The Industrial Diet: the Degradation of Food and the Struggle for Healthy Eating, Vancouver, uBC Press.

Wise, Timothy A. (2014), «Monsanto Meets it Match in the Birthplace of Maize», Triple Crisis: Global Perspectives on Finance, Development and Environment, en http://triplecrisis.com/monsanto-meets-its-match-in-the-birthplace-of - maize? ut m_source = G DAE +Subscribers $\&$ utm campaign $=591 \mathrm{~b} 2 \mathrm{a} 7943-\mathrm{TW}_{-}$Monsanto_5_12_2014\&utm_ medium $=$ email\&utm_term $=0 \_72$ d4918ff9-591b2a7943-46746905 (consultado el 12 de 2014). 
